\title{
The nucleus accumbens shell and the dorsolateral striatum mediate the reinforcing effects of cocaine through a serial connection
}

\author{
Maartje M.J. Veeneman ${ }^{a}$, Ruth Damsteegt ${ }^{a}$ and Louk J.M.J. Vanderschuren ${ }^{a, b}$
}

\begin{abstract}
The reinforcing and addictive properties of cocaine are thought to rely on the dopaminergic innervation of the striatum. The ventromedial [i.e. nucleus accumbens shell (NAcc) shell] and dorsolateral [dorsolateral striatum (DLS)] regions of the striatum are serially connected, and it is thought that slowly developing neuroadaptations are responsible for the recruitment of the DLS in mediating habitual drug use after extended drug experience.

Remarkably, we have recently shown that the DLS is also involved in cocaine self-administration after limited use, to modulate the reinforcing properties of the drug, a function usually ascribed to the NAcc shell. Here, we investigated whether the involvement of the DLS in cocaine reinforcement requires dopaminergic activity within the NAcc shell, by performing a pharmacological disconnection study. We infused the dopamine receptor antagonist $\alpha$-flupenthixol unilaterally into the NAcc shell and infused this same antagonist into the contralateral DLS, thereby disrupting dopaminergic interconnectivity within the striatum. We show that this disconnection results in
\end{abstract}

\begin{abstract}
increased responding for cocaine under a fixed ratio-1 schedule of reinforcement in rats with limited cocaine experience. These data suggest that a functional dopaminergic interaction between the NAcc shell and the DLS mediates cocaine reinforcement during the early stages of drug use. Behavioural Pharmacology 26:193-199 Copyright (c) 2015 Wolters Kluwer Health, Inc. All rights reserved.
\end{abstract}

Behavioural Pharmacology 2015, 26:193-199

Keywords: cocaine, dopamine receptors, dorsolateral striatum, nucleus accumbens shell, rat, reinforcement, self-administration

aDDepartment of Translational Neuroscience, Brain Center Rudolf Magnus, University Medical Center Utrecht and ${ }^{b}$ Department of Animals in Science and Society, Division of Behavioural Neuroscience, Faculty of Veterinary Medicine, Utrecht University, Utrecht, The Netherlands

Correspondence to Louk J.M.J. Vanderschuren, PhD, Department of Animals in Science and Society, Division of Behavioural Neuroscience, Faculty of Veterinary Medicine, Utrecht University, Yalelaan 2, 3584 CM Utrecht, The Netherlands E-mail: I.j.m.j.vanderschuren@uu.nl

Received 19 February 2014 Accepted as revised 6 September 2014

and professional activities, and continued drug use despite awareness of its adverse consequences (American Psychiatric Association, 2000, 2013). It has been hypothesized that drug-induced functional changes that progress from the ventromedial to the dorsolateral striatum (DLS) play an important role in the descent from casual, recreational cocaine use into addiction (Everitt and Robbins, 2005; Pierce and Vanderschuren, 2010; Everitt, 2014). It is well known that the DLS is involved in stimulus-response habit learning (Packard and Knowlton, 2002; Yin et al., 2004, 2006; Faure et al., 2005; Quinn et al., 2013; Smith and Graybiel, 2013). It is therefore thought that the DLS is also responsible for the habitual, stimulus-driven drug use that is seen in the addicted state (Everitt and Robbins, 2005; Pierce and Vanderschuren, 2010; Everitt, 2014). Indeed, dopamine activity has been found to be increased in the dorsal, but not ventral, striatum when addicted individuals are exposed to cocaine cues (Volkow et al., 2006; Wong et al., 2006). Moreover, adaptations in dopamine signalling gradually spread and intensify from the ventral to the dorsal striatum in nonhuman primates that self-administer cocaine for prolonged periods of time (Moore et al., 1998; Letchworth et al., 2001; Nader et al., 2002; Porrino et al., 2004). Recent studies in rats have also shown that
With prolonged drug use, however, recreational cocaine taking can devolve into addiction, which is characterized by, among others, the occurrence of drug-directed behaviour at the expense of previously important social 
dopamine $D_{2}$ receptor expression in the ventral and dorsal striatum decreases after cocaine self-administration in rats (Conrad et al., 2010; Besson et al., 2013), whereby that larger changes were observed after a prolonged selfadministration history (Besson et al., 2013). Behavioural analysis of the role of the DLS in addictive behaviour has demonstrated that dopamine receptor blockade within the DLS reduces well-established, cue-controlled cocaine seeking (Vanderschuren et al., 2005; Belin and Everitt, 2008; Murray et al., 2012) and that pharmacological inactivation of the DLS reduces habitual or punished cocaine seeking in rats (Zapata et al., 2010; Jonkman et al., 2012).

However, the role of the DLS in cocaine use may not be restricted to its habitual aspects after prolonged drug selfadministration. We, and others, have recently shown that dopamine in the DLS mediates the reinforcing properties of cocaine in animals with limited drug experience (Veeneman et al., 2012a; Willuhn et al., 2012). This raised the question of whether the ventromedial striatum and the DLS mediate cocaine reinforcement in concert during the early stages of cocaine use. To answer this, we performed a pharmacological disconnection study (Everitt et al., 1991). In this experiment, dopaminergic neurotransmission was blocked in the NAcc shell in one hemisphere, and in the DLS in the contralateral hemisphere. We hypothesized that, if a serial dopaminergic connection between the NAcc shell and the DLS (Nauta et al., 1978; Haber et al., 2000; Ferreira et al., 2008; Van Dongen et al., 2009) mediates cocaine reinforcement, then unilateral suppression of dopaminergic neurotransmission in the NAcc shell combined with suppression of dopaminergic neurotransmission in the contralateral DLS would result in a response pattern that is similar to a bilateral suppression of dopaminergic neurotransmission in the DLS.

\section{Methods \\ Subjects}

A total of 16 male Wistar rats (Charles River, Sulzfeld, Germany) weighing $250 \pm 15 \mathrm{~g}$ at the time of arrival were used. The animals were housed two per cage (Macrolon cages: $40 \times 26 \times 20 \mathrm{~cm}$ ) in climate-controlled rooms (temperature: $21 \pm 2^{\circ} \mathrm{C}, 60-65 \%$ relative humidity) under a reversed $12 \mathrm{~h}$ day/night cycle with lights off at $07: 00 \mathrm{~h}$. A small block of wood was used as cage enrichment; regular chow (SDS, Essex, UK) and water were freely available. Animals were allowed to habituate to the housing conditions for at least 9 days before they underwent surgery. Before the start of the self-administration sessions, rats were subjected to scheduled feeding of $20 \mathrm{~g}$ chow (SDS) per day, given at least $1 \mathrm{~h}$ after the sessions to avoid association with the selfadministration sessions. This amount was sufficient to maintain body weight and growth. Throughout the experiment, water was freely available, except during selfadministration sessions. Self-administration sessions were carried out between 09:00 and 18:00 h, for 5-7 days a week.
Experiments were approved by the Animal Ethics Committee of Utrecht University, the Netherlands, and were conducted in agreement with Dutch laws (Wet op de dierproeven, 1996) and European regulations (Guideline 86/609/EEC).

\section{Surgery}

Rats were anaesthetized with ketamine hydrochloride (75 mg/kg intramuscularly) and medetomidine $(0.4 \mathrm{mg} / \mathrm{kg}$ subcutaneously) and a catheter was placed in the right jugular vein. Catheters consisted of a silastic tube connected to a guide cannula and a mesh on the base of the cannula (CamCaths, Cambridge, UK). The cannula was secured by placing the mesh below the skin on the back of the animal. Following catheter implantation, rats were positioned in a stereotaxic apparatus and two guide cannulae (Plastics One Inc., Roanoke, Virginia, USA) were implanted $1 \mathrm{~mm}$ above target structures. One cannula was aimed at the NAcc shell and the other cannula was implanted contralaterally, aimed at the DLS. The left or right positions of the cannulae aiming at the NAcc shell and DLS were counterbalanced between individual animals. Coordinates relative to bregma (Paxinos and Watson, 2005) were as follows: NAcc shell - anteroposterior $+1.2 \mathrm{~mm}$, mediolateral $\pm 2.8 \mathrm{~mm}$, dorsoventral $-7.5 \mathrm{~mm}$, at an angle of $10^{\circ}$; DLS $-+1.2 \mathrm{~mm}$ anteroposterior, $\pm 4.2 \mathrm{~mm}$ mediolateral, $-3.7 \mathrm{~mm}$ dorsoventral at an angle of $10^{\circ}$. Cannulae were fixed in place using stainless steel screws and dental acrylic. To prevent occlusion of the cannulae, a stainless steel stylet was inserted into each guide cannula. All objects and instruments used during surgery were thoroughly sterilized. Carprofen $(5 \mathrm{mg} / \mathrm{kg}$, subcutaneously) was administered before and twice after surgery to treat postsurgical pain. To prevent infection, rats were treated with gentamycin $(5 \mathrm{mg} / \mathrm{kg}$, subcutaneously) before surgery and for 5 consecutive days after surgery. After a recovery period of at least 9 days, the rats were trained to self-administer cocaine.

\section{Apparatus}

All subjects were trained and tested in operant conditioning chambers $(29.5 \mathrm{~cm}$ length, $24 \mathrm{~cm}$ width, $25 \mathrm{~cm}$ height; Med Associates, Georgia, Vermont, USA) situated in light and sound-attenuating cubicles equipped with a ventilation fan. Each chamber was equipped with two $4.8-\mathrm{cm}$ wide retractable levers placed $11.7 \mathrm{~cm}$ apart and $6 \mathrm{~cm}$ from the grid floor. A cue light was present above each lever $(28 \mathrm{~V}, 100 \mathrm{~mA})$ and a house light $(28 \mathrm{~V}, 100 \mathrm{~mA})$ was located on the opposite wall. Food pellets could be delivered at the wall opposite the levers through a dispenser. Cocaine infusions were controlled by a syringe pump placed on top of the cubicles. Polyethylene tubing ran from the syringe placed in the syringe pump through a swivel to the cannula on the subject's back; in the operant chamber the tubing was shielded with a metal spring. Priming infusions of cocaine to stimulate self-administration were 
Fig. 1
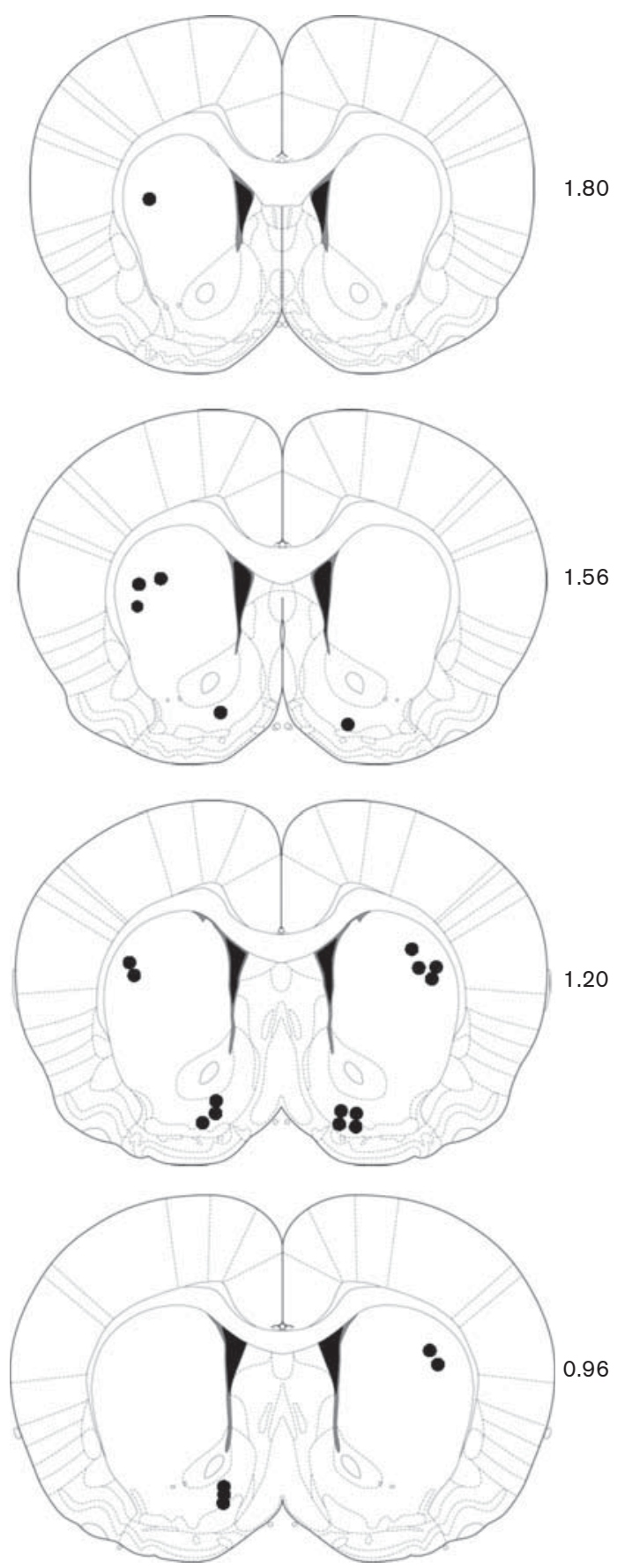

Schematic representation of NAcc shell and DLS infusion sites in coronal sections. Numbers indicate the distances anterior to bregma in $\mathrm{mm}$. Adapted from Paxinos and Watson (2005). Note that the left or right position of the cannulae aiming at the NAcc shell and DLS was counterbalanced between individual animals, so that the NAcc shell and DLS infusion sites are represented in both hemispheres. DLS, dorsolateral striatum; NAcc, nucleus accumbens.

never given. After each session, catheters were flushed with $0.15 \mathrm{ml}$ heparinized saline. Experimental events and data recording were controlled by procedures written in
MedState Notation using MED-PC (Med Associates, Georgia, VT, USA) for Windows.

\section{Microinfusions}

Intracerebral microinfusions were made through $33 \mathrm{G}$ injector cannulae (Plastics One Inc.) that extended $1.0 \mathrm{~mm}$ below the end of the guide cannulae. Using a syringe pump (Harvard Apparatus; Instech Laboratories, Plymouth Meeting, Pennsylvania, USA), bilateral infusions $(0.3 \mu \mathrm{l} / \mathrm{side})$ were made over $60 \mathrm{~s}$. After the infusion, the injector cannulae were left in place for another $60 \mathrm{~s}$ to allow for diffusion. Next, the injector cannulae were removed and rats were placed into the self-administration chambers. Self-administration sessions began $7 \mathrm{~min}$ after the start of the microinfusion.

\section{Cocaine self-administration}

Rats were trained to self-administer cocaine under a fixed ratio-1 (FR-1) schedule of reinforcement as described previously (Veeneman et al., 2012a). During the 2-h selfadministration sessions, two levers were present: an active lever and an inactive lever. The left or right position of the active and inactive levers was counterbalanced for individual animals. Pressing on the active lever resulted in the infusion of $0.25 \mathrm{mg}$ cocaine in $0.1 \mathrm{ml}$ saline delivered over $5.6 \mathrm{~s}$, retraction of the levers, and the switching off of the house light. During the infusion, a cue light above the lever was switched on, followed by a 20 -s time-out period, after which the levers were reintroduced and the house light illuminated. When rats showed stable responding under this schedule, defined as less than $10 \%$ variation over three sessions, they received an infusion with saline into the unilateral NAcc shell and contralateral DLS to habituate them to the infusion procedure. After at least 2 days of stable responding after the habituation infusion, rats received the following combinations of infusions: saline into the NAcc shell and saline into the contralateral DLS; $\alpha$-flupenthixol $(15.0 \mu \mathrm{g})$ into the NAcc shell and saline into the contralateral DLS; saline into the NAcc shell and $\alpha$-flupenthixol $(15.0 \mu \mathrm{g})$ into the contralateral DLS; and $\alpha$-flupenthixol $(15.0 \mu \mathrm{g})$ into the NAcc shell and $\alpha$-flupenthixol $(15.0 \mu \mathrm{g})$ into the contralateral DLS. Each animal received every combination of infusions before self-administration sessions, but in a different order, and test sessions were separated by at least one selfadministration session without treatment.

\section{Histology}

After completion of the microinfusions, rats were killed using an overdose of pentobarbital natrium. Next, the brains were removed, immediately fresh-frozen on dry ice, and stored at $-80^{\circ} \mathrm{C}$. Coronal sections $(20 \mu \mathrm{m})$ were sliced on a cryostat and every fifth section was mounted and stained with hematoxylin and eosin. Cannula placements (Fig. 1) were verified under a light microscope. 


\section{Drugs}

Cocaine-HCl (Bufa BV, Uitgeest, the Netherlands) and cis-(Z)-flupenthixol dihydrochloride (Sigma, Zwijndrecht, the Netherlands) were dissolved in sterile physiological saline $(0.9 \% \mathrm{NaCl})$.

\section{Statistics}

Cocaine self-administration was analysed using a repeatedmeasures analysis of variance with treatment as the withinsubjects factor, and post-hoc comparisons were made using two-tailed paired $t$-tests. The criterion for a main effect of treatment was set at a $P$ value less than 0.05 . The criterion for statistical significance for the post-hoc analysis was corrected for multiple (i.e. six) comparisons. Hence, $P$ values less than 0.008 were considered statistically significant. Data were analysed using IBM SPSS Statistics 20.0 (IBM Corp., Armonk, New York, USA).

\section{Results}

Four animals were excluded from the analysis because of catheter failure $(n=2)$ or incorrect cannula placement $(n=2)$, which left $n=12$ animals in the final analysis. After self-administration had stabilized under an FR-1 schedule of reinforcement, which took $12 \pm 1$ sessions, we unilaterally infused $\alpha$-flupenthixol or saline into the NAcc shell and into the contralateral DLS. The entire experiment lasted for $39.5 \pm 2.6$ sessions, during which the animals took $1244 \pm 135$ infusions, resulting in a total intake of $311.2 \pm 33.6 \mathrm{mg}$ cocaine.

Figure 2 shows that the combination of infusions affected cocaine self-administration $\left[F_{(3,33)}=11.16, \quad P<0.001\right]$. Unilateral administration of $\alpha$-flupenthixol into the NAcc shell combined with administration of $\alpha$-flupenthixol into the contralateral DLS increased responding, compared with saline in the NAcc shell and saline in the DLS $\left[t_{11}=-6.05, P<0.001\right]$ and saline in the NAcc shell and $\alpha$-flupenthixol in the DLS $\left[t_{11}=-3.97, P=0.002\right]$. None of the other post-hoc comparisons were significant. Importantly, there was no effect of unilateral administration of $\alpha$-flupenthixol into the NAcc shell combined with saline administration into the contralateral DLS, compared with saline infusions in both the unilateral NAcc shell and the contralateral DLS $\left[t_{11}=-1.99\right.$, NS], nor was there an effect of unilateral saline administration into the NAcc shell combined with of $\alpha$-flupenthixol administration into the contralateral DLS, compared with saline infusions in both the unilateral NAcc shell and the contralateral DLS $\left[t_{11}=-1.18, \mathrm{NS}\right]$. As a result of the increase in responding, infusion of $\alpha$-flupenthixol into the NAcc shell combined with administration of $\alpha$-flupenthixol into the contralateral DLS also increased cocaine intake (in mg: saline in both NAcc shell and DLS: $7.9 \pm 0.6$; $\alpha$-flupenthixol in NAcc shell and saline in DLS: $9.6 \pm 0.9$; saline in NAcc shell and $\alpha$-flupenthixol in DLS: $8.6 \pm 0.6$; $\alpha$-flupenthixol in both NAcc shell and DLS: $12.2 \pm 1.0)$. There was no significant effect of the
Fig. 2

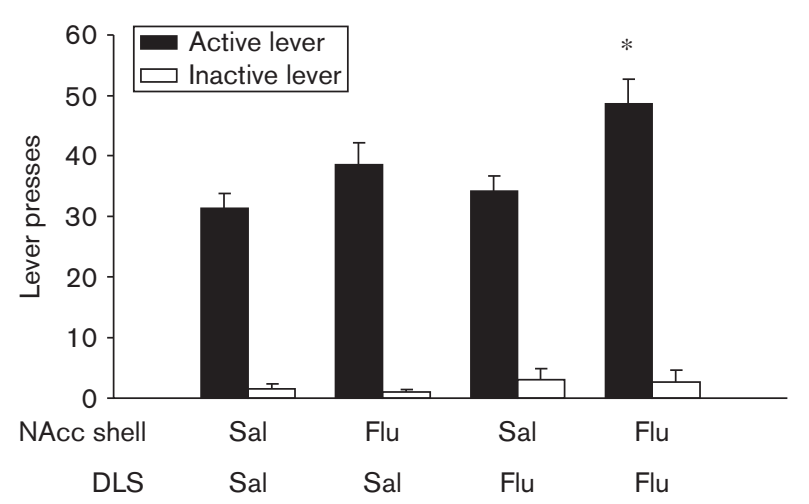

Effect of unilateral $\alpha$-flupenthixol infusions into the NAcc shell and contralateral DLS on intravenous cocaine self-administration under an FR-1 schedule of reinforcement. The mean \pm SEM number of active and inactive lever presses during a 2 -h self-adminstration session is shown (sal, saline; flu, $\alpha$-flupenthixol). ${ }^{\star} P<0.001$, different from sal/sal (two-tailed paired $t$-test). DLS, dorsolateral striatum; NAcc, nucleus accumbens.

combination of infusions on inactive lever presses $\left[F_{(3,33)}=0.45, \mathrm{NS}\right]$.

\section{Discussion}

The results of this study show that pharmacologically disconnecting the NAcc shell from the DLS by unilaterally suppressing dopaminergic neurotransmission in the NAcc shell and in the contralateral DLS increases responding for cocaine under an FR-1 schedule of reinforcement in rats with limited cocaine experience. This effect is reminiscent of the increase in cocaine selfadministration under an FR-1 schedule of reinforcement after bilateral suppression of dopaminergic neurotransmission in the DLS (Veeneman et al., 2012a; Willuhn et al., 2012). The increase in responding indicates that the animals experienced a reduction in the subjective value of a cocaine infusion as a result of dopamine receptor blockade. As a consequence, the animals compensate for the reduced effect of cocaine by enhancing the rate of responding under an FR-1 schedule of reinforcement (De Wit and Wise, 1977; Ettenberg et al., 1982; Caine and Koob, 1994), akin to the increases in the number of infusions taken when unit doses of cocaine are reduced (Gerber and Wise, 1989; Zittel-Lazarini et al., 2007; Veeneman et al., 2012a). This finding suggests that there is a serial dopaminergic connection between the NAcc shell and the DLS that mediates the reinforcing properties of cocaine.

The present findings add to the evidence that the involvement of DLS dopamine is not restricted to advanced stages of cocaine addiction. Thus, increases in DLS dopamine signalling have been found in rats with limited cocaine experience during context-induced 
Fig. 3
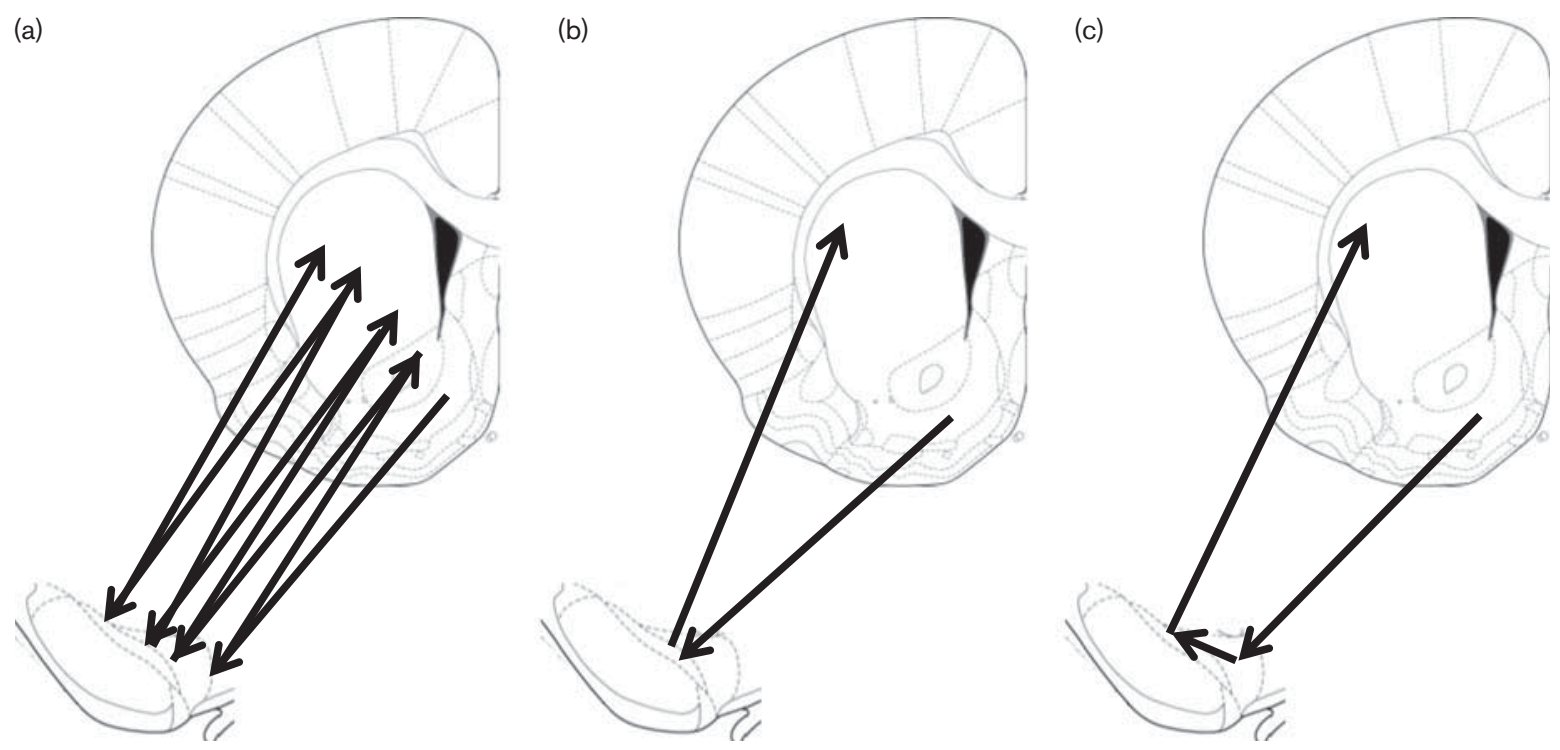

Possible mechanisms for a functional serial connection between the NAcc shell and DLS mediating cocaine reinforcement. (a) Spiralling projections that ascend from ventral striatal areas to dorsal striatal areas through the VTA and SNc (Nauta et al., 1978; Haber et al., 2000). (b) The NAcc shell projects through the medial SNc directly to the DLS (Van Dongen et al., 2009). (c) The NAcc shell projects to the VTA, which in turn projects to the SNc, which finally projects to the DLS (Ferreira et al., 2008). DLS, dorsolateral striatum; NAcc, nucleus accumbens; SNc, substantia nigra pars compacta; VTA, ventral tegmental area.

cocaine seeking (Gabriele et al., 2012), as well as during active responding for the drug (Willuhn et al., 2012). Interestingly, in the latter study, increases in dopamine signalling developed within 3 weeks of cocaine selfadministration under an FR-1 schedule of reinforcement. The emergence of this dopamine signal was prevented by a lesion of the NAcc core, which reinforces the notion that serial connections between ventral striatal regions and the DLS underlie the reinforcing effects of cocaine and associated cues [Willuhn et al., 2012; present study, see also the study by Belin and Everitt, 2008]. Moreover, blockade of DLS dopamine receptors reduces the reinforcing effects of cocaine in rats (Veeneman et al., 2012a; Willuhn et al., 2012), consistent with the observation that cocaine self-administration in nonaddicted users increased dopamine signalling in the putamen (the human equivalent of the DLS; Cox et al., 2009).

It is unlikely that the changes in cocaine selfadministration after asymmetrical dopamine receptor blockade in the NAcc shell and DLS are secondary to an increase in general activity. First, we did not observe a change in inactive lever presses. Second, we have previously found that bilateral infusion of $\alpha$-flupenthixol into the DLS does not affect responding for sucrose, whereas $\alpha$-flupenthixol infusion into the NAcc shell reduces it (Veeneman et al., 2012a). Third, given the wellestablished role of ventral and dorsal striatal dopamine in the hyperactivity and stereotypy, respectively, induced by psychostimulant drugs (Kelly et al., 1975; Delfs et al.,
1990), striatal dopamine receptor blockade would be expected to reduce, rather than enhance, the effect on psychomotor activity induced by self-administered cocaine. The drug doses in the present study were based on previous work in our own and other laboratories (Arroyo et al., 1998; Vanderschuren et al., 2005; Belin and Everitt, 2008; Murray et al., 2012; Veeneman et al., 2012a, 2012b), which has demonstrated that the dose of cocaine used here supports reliable self-administration under a variety of reinforcement schedules and that the dose of $\alpha$-flupenthixol used profoundly alters cocaine self-administration, depending upon the brain region and reinforcement schedule. Nevertheless, the use of single drug doses presents a limitation of the present study. Further experimentation is therefore warranted to investigate the involvement of the serial dopaminergic connection between the NAcc shell and DLS in cocaine self-administration, using different drug doses and reinforcement schedules, as well as other (natural and drug) reinforcers.

Anatomical studies have indicated three possible routes by which a functional serial connection between the NAcc shell and the DLS may mediate cocaine reinforcement. The first comprises spiral-like projections from ventral striatal areas to dorsal striatal areas through their projections to mesencephalic dopaminergic cell bodies in the ventral tegmental area (VTA) and substantia nigra pars compacta (SNc) (Fig. 3a) (Nauta et al., 1978; Haber et al., 2000). This series of spiralling projections has been implicated in, possibly habitual, drug use after extended 
self-administration experience. First, these spiral-like projections offer a plausible explanation for the gradual functional adaptations that progress from ventral to dorsal in the striatum with increasing cocaine-taking experience in primates (Moore et al., 1998; Letchworth et al., 2001; Nader et al., 2002; Porrino et al., 2004). Second, a decrease in cue-controlled drug seeking has been shown in rats after a unilateral lesion of the NAcc core and contralateral blockade of dopamine receptors in the DLS, which may effectively block information processing through this spiral (Belin and Everitt, 2008). It is important to note that it took many months of cocaine self-administration before neural adaptations reached the dorsal striatum in primates (Moore et al., 1998; Letchworth et al., 2001; Nader et al., 2002; Porrino et al., 2004), and the involvement of the core-to-DLS pathway in cue-controlled drug seeking was also observed in animals that were well trained to respond for cocaine-associated cues (Belin and Everitt, 2008). In our experiments, however, the involvement of the DLS in cocaine self-administration was already apparent after limited drug-taking experience, which raises the question of whether this striato-nigro-striatal spiral can cause cocaine-induced neural adaptations to reach the DLS after a relatively small number of drug-taking episodes. Interestingly, it has also been shown that the NAcc shell may influence DLS function through shorter pathways. Anterograde tracing from the NAcc shell combined with retrograde tracing from the DLS has shown an overlap in labeled neurons in the medial SNc and lateral VTA (Van Dongen et al., 2009). Furthermore, stimulation of neurons in the NAcc shell induced an inhibition of dopaminergic neurons located in the medial SNc and lateral VTA that project to the DLS (Van Dongen et al., 2009). Thus, there may be a pathway that projects from the NAcc shell to the DLS crossing the medial SNc and lateral VTA only once (Fig. 3b). Alternatively, anterograde tracing from the VTA has revealed that the VTA directly projects to the SNc (Ferreira et al., 2008), suggesting that projections within the VTA-nigral complex may also facilitate the connection between the NAcc shell and the DLS (Fig. 3c). If the DLS receives information about the reinforcing effects of cocaine through the NAcc shell, then these latter pathways are likely candidates to be the neural substrate of the early involvement of the DLS in cocaine selfadministration.

In sum, our study provides new insight into the role of dopaminergic innervation of the striatum in cocaine taking after limited drug experience. We show that the DLS dopamine modulates cocaine self-administration in concert with dopamine in the NAcc shell, suggesting that integrated function of the striatum mediates the reinforcing properties of cocaine.

\section{Acknowledgements}

Supported by ZonMw (the Netherlands Organisation for Health Research and Development) Grant 91207006 (to L.J.
M.J.V., P. Voorn and A.B. Smit). ZonMw (the Netherlands Organisation for Health Research and Development)/National Institute on Drug Abuse (NIDA) Collaborative Grant 6060600-97-211 (to L.J.M.J.V. and R.C. Pierce).

\section{Conflicts of interest}

There are no conflicts of interest.

\section{References}

American Psychiatric Association (2000). Diagnostic and statistical manual of mental disorders, IV-TR edn. Washington, DC, USA: American Psychiatric Association.

American Psychiatric Association (2013). DSM-5: Diagnostic and statistical manual of mental disorders. Washington, DC, USA: American Psychiatric Association.

Arroyo M, Markou A, Robbins TW, Everitt BJ (1998). Acquisition, maintenance and reinstatement of intravenous cocaine self-administration under a secondorder schedule of reinforcement in rats: effects of conditioned cues and continuous access to cocaine. Psychopharmacology (Berl) 140:331-344.

Bachtell RK, Whisler K, Karanian D, Self DW (2005). Effects of intra-nucleus accumbens shell administration of dopamine agonists and antagonists on cocaine-taking and cocaine-seeking behaviors in the rat. Psychopharmacology (Berl) 183:41-53

Bari AA, Pierce RC (2005). D1-like and D2 dopamine receptor antagonists administered into the shell subregion of the rat nucleus accumbens decrease cocaine, but not food, reinforcement. Neuroscience 135:959-968.

Belin D, Everitt BJ (2008). Cocaine seeking habits depend upon dopaminedependent serial connectivity linking the ventral with the dorsal striatum. Neuron 57:432-441.

Besson M, Pelloux Y, Dilleen R, Theobald DE, Lyon A, Belin-Rauscent A, et al. (2013). Cocaine modulation of frontostriatal expression of Zif268, D2, and 5 -HT2c receptors in high and low impulsive rats. Neuropsychopharmacology 38:1963-1973.

Caine SB, Koob GF (1994). Effects of dopamine D-1 and D-2 antagonists on cocaine self-administration under different schedules of reinforcement in the rat. J Pharmacol Exp Ther 270:209-218.

Caine SB, Heinrichs SC, Coffin VL, Koob GF (1995). Effects of the dopamine D-1 antagonist SCH 23390 microinjected into the accumbens, amygdala or striatum on cocaine self-administration in the rat. Brain Res 692:47-56.

Conrad KL, Ford K, Marinelli M, Wolf ME (2010). Dopamine receptor expression and distribution dynamically change in the rat nucleus accumbens after withdrawal from cocaine self-administration. Neuroscience 169:182-194.

Cox SM, Benkelfat C, Dagher A, Delaney JS, Durand F, McKenzie SA, et al. (2009). Striatal dopamine responses to intranasal cocaine self-administration in humans. Biol Psychiatry 65:846-850.

Delfs JM, Schreiber L, Kelley AE (1990). Microinjection of cocaine into the nucleus accumbens elicits locomotor activation in the rat. $J$ Neurosci 10:303-310

De Wit H, Wise RA (1977). Blockade of cocaine reinforcement in rats with the dopamine receptor blocker pimozide, but not with the noradrenergic blockers phentolamine or phenoxybenzamine. Can J Psychol 31:195-203.

Ettenberg A, Pettit HO, Bloom FE, Koob GF (1982). Heroin and cocaine intravenous self-administration in rats: mediation by separate neural systems. Psychopharmacology 78:204-209.

Everitt BJ (2014). Neural and psychological mechanisms underlying compulsive drug seeking habits and drug memories - indications for novel treatments of addiction. Eur J Neurosci 40:2163-2182.

Everitt BJ, Robbins TW (2005). Neural systems of reinforcement for drug addiction: from actions to habits to compulsion. Nat Neurosci 8:1481-1489.

Everitt BJ, Morris KA, O'Brien A, Robbins TW (1991). The basolateral amygdalaventral striatal system and conditioned place preference: further evidence of limbic-striatal interactions underlying reward-related processes. Neuroscience 42:1-18.

Faure A, Haberland U, Condé F, El Massioui N (2005). Lesion to the nigrostriatal dopamine system disrupts stimulus-response habit formation. J Neurosci 25:2771-2780.

Ferreira JG, Del Fava F, Hasue RH, Shammah-Lagnado SJ (2008). Organization of ventral tegmental area projections to the ventral tegmental area-nigral complex in the rat. Neuroscience 153:196-213.

Gabriele A, Pacchioni AM, See RE (2012). Dopamine and glutamate release in the dorsolateral caudate putamen following withdrawal from cocaine selfadministration in rats. Pharmacol Biochem Behav 103:373-379. 
Gerber GJ, Wise RA (1989). Pharmacological regulation of intravenous cocaine and heroin self-administration in rats: a variable dose paradigm. Pharmacol Biochem Behav 32:527-531.

Haber SN, Fudge JL, McFarland NR (2000). Striatonigrostriatal pathways in primates form an ascending spiral from the shell to the dorsolateral striatum. J Neurosci 20:2369-2382.

Ikemoto S (2003). Involvement of the olfactory tubercle in cocaine reward: intracranial self-administration studies. J Neurosci 23:9305-9311.

Jonkman S, Pelloux Y, Everitt BJ (2012). Differential roles of the dorsolateral and midlateral striatum in punished cocaine seeking. $J$ Neurosci 32:4645-4650.

Kelly PH, Seviour PW, Iversen SD (1975). Amphetamine and apomorphine responses in the rat following 6-OHDA lesions of the nucleus accumbens septi and corpus striatum. Brain Res 94:507-522.

Koob GF, Sanna PP, Bloom FE (1998). Neuroscience of addiction. Neuron 21:467-476.

Letchworth SR, Nader MA, Smith HR, Friedman DP, Porrino LJ (2001). Progression of changes in dopamine transporter binding site density as a result of cocaine self-administration in rhesus monkeys. $J$ Neurosci 21: 2799-2807.

Moore RJ, Vinsant SL, Nader MA, Porrino LJ, Friedman DP (1998). Effect of cocaine self-administration on dopamine D2 receptors in rhesus monkeys. Synapse 30:88-96.

Murray JE, Belin D, Everitt BJ (2012). Double dissociation of the dorsomedial and dorsolateral striatal control over the acquisition and performance of cocaine seeking. Neuropsychopharmacology 37:2456-2466.

Nader MA, Daunais JB, Moore T, Nader SH, Moore RJ, Smith HR, et al. (2002). Effects of cocaine self-administration on striatal dopamine systems in rhesus monkeys: initial and chronic exposure. Neuropsychopharmacology 27:35-46.

Nauta WJ, Smith GP, Faull RL, Domesick VB (1978). Efferent connections and nigral afferents of the nucleus accumbens septi in the rat. Neuroscience 3:385-401.

Packard MG, Knowlton BJ (2002). Learning and memory functions of the basal ganglia. Annu Rev Neurosci 25:563-593.

Paxinos G, Watson C (2005). The rat brain in stereotaxic coordinates. 5th ed. San Diego: Academic Press.

Pierce RC, Kumaresan V (2006). The mesolimbic dopamine system: the final common pathway for the reinforcing effect of drugs of abuse? Neurosci Biobehav Rev 30:215-238.

Pierce RC, Vanderschuren LJMJ (2010). Kicking the habit: the neural basis of ingrained behaviors in cocaine addiction. Neurosci Biobehav Rev 35: 212-219.

Porrino LJ, Lyons D, Smith HR, Daunais JB, Nader MA (2004). Cocaine selfadministration produces a progressive involvement of limbic, association, and sensorimotor striatal domains. J Neurosci 24:3554-3562.
Quinn JJ, Pittenger C, Lee AS, Pierson JL, Taylor JR (2013). Striatum-dependent habits are insensitive to both increases and decreases in reinforcer value in mice. Eur J Neurosci 37:1012-1021.

Rodd-Henricks ZA, McKinzie DL, Li TK, Murphy JM, McBride WJ (2002). Cocaine is self-administered into the shell but not the core of the nucleus accumbens of Wistar rats. J Pharmacol Exp Ther 303:1216-1226.

Smith KS, Graybiel AM (2013). A dual operator view of habitual behavior reflecting cortical and striatal dynamics. Neuron 79:361-374.

Van Dongen YC, Kolomiets BP, Groenewegen HJ, Thierry AM, Deniau JM (2009). A subpopulation of mesencephalic dopamine neurons interfaces the shell of nucleus accumbens and the dorsolateral striatum in rats. In: Groenewegen HJ, Berendse HW, Cools AR, Voorn P, Mulder AB, editors. The basal ganglia IX. New York: Springer. pp. 119-130.

Vanderschuren LJMJ, Di Ciano P, Everitt BJ (2005). Involvement of the dorsa striatum in cue-controlled cocaine seeking. J Neurosci 25:8665-8670.

Veeneman MMJ, Broekhoven MH, Damsteegt R, Vanderschuren LJMJ (2012a). Distinct contributions of dopamine in the dorsolateral striatum and nucleus accumbens shell to the reinforcing properties of cocaine. Neuropsychopharmacology 37:487-498.

Veeneman MMJ, van Ast M, Broekhoven MH, Limpens JHW, Vanderschuren LJMJ (2012b). Seeking-taking chain schedules of cocaine and sucrose selfadministration: effects of reward size, reward omission, and $\alpha$-flupenthixol. Psychopharmacology (Berl) 220:771-785.

Volkow ND, Wang GJ, Telang F, Fowler JS, Logan J, Childress AR, et al. (2006). Cocaine cues and dopamine in dorsal striatum: mechanism of craving in cocaine addiction. J Neurosci 26:6583-6588.

Willuhn I, Burgeno LM, Everitt BJ, Phillips PE (2012). Hierarchical recruitment of phasic dopamine signaling in the striatum during the progression of cocaine use. Proc Natl Acad Sci USA 109:20703-20708.

Wise RA (2004). Dopamine, learning and motivation. Nat Rev Neurosci 5:483-494.

Wong DF, Kuwabara H, Schretlen DJ, Bonson KR, Zhou Y, Nandi A, et al. (2006). Increased occupancy of dopamine receptors in human striatum during cueelicited cocaine craving. Neuropsychopharmacology 31:2716-2727.

Yin HH, Knowlton BJ, Balleine BW (2004). Lesions of dorsolateral striatum preserve outcome expectancy but disrupt habit formation in instrumental learning. Eur J Neurosci 19:181-189.

Yin $\mathrm{HH}$, Knowlton BJ, Balleine BW (2006). Inactivation of dorsolateral striatum enhances sensitivity to changes in the action-outcome contingency in instrumental conditioning. Behav Brain Res 166:189-196.

Zapata A, Minney VL, Shippenberg TS (2010). Shift from goal-directed to habitual cocaine seeking after prolonged experience in rats. $J$ Neurosci 30: 15457-15463.

Zittel-Lazarini A, Cador M, Ahmed SH (2007). A critical transition in cocaine selfadministration: behavioral and neurobiological implications. Psychopharmacology (Berl) 192:337-346. 